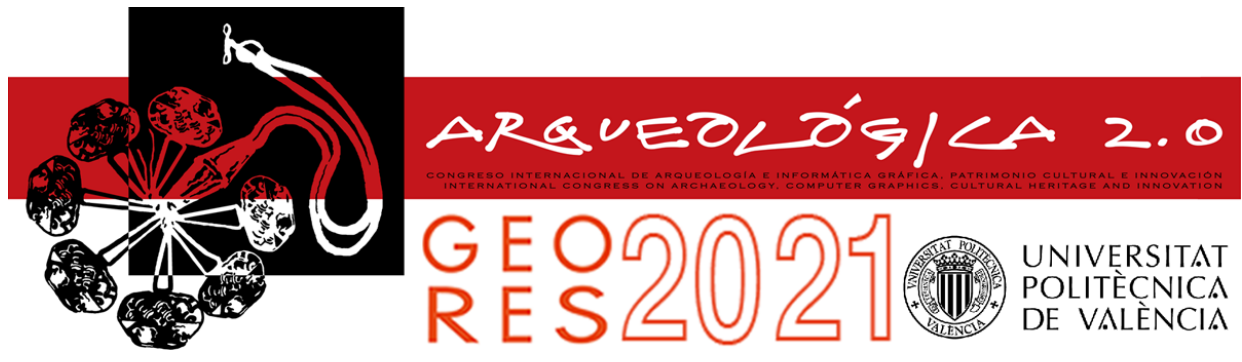

Proceedings of the joint international event $9^{\text {th }}$ ARQUEOLÓGICA

$2.0 \& 3^{\text {rd }}$ GEORES

Valencia (Spain).

26-28 April 2021

\title{
THE COMPLEX OF SANTA CROCE IN RAVENNA AS A CASE STUDY: INTEGRATION OF 3D TECHNIQUES FOR SURVEYING AND MONITORING OF A HISTORICAL SITE
}

\author{
Gabriele Bitellia,b, ${ }^{*}$, Ester Barbieri ${ }^{\mathrm{b}}$, Valentina Alena Girellia,b, Alessandro Lambertinia ${ }^{a}$, Emanuele \\ Mandanicia , Eleonora Melandri ${ }^{b}$, Domenico Simone Roggio ${ }^{b}$, Angela Santangelo ${ }^{\mathrm{b}, \mathrm{c}}$, Maria \\ Alessandra Tinia , Simona Tondellib,c, Andrea Ugolinib,c \\ a DICAM, Department of Civil, Chemical, Environmental and Materials Engineering, Alma Mater Studiorum, University of Bologna, Viale \\ Risorgimento 2, 40136 Bologna, Italy.gabriele.bitelli@unibo.it; valentina.girelli@unibo.it; alessandro.lambertini@unibo.it; \\ emanuele.mandanici@unibo.it; mariaalessandra.tini@unibo.it \\ b Interdepartmental Centre for Industrial Research in Building and Construction, Alma Mater Studiorum, University of Bologna, Via del \\ Lazzaretto 15/5, 40131 Bologna, Italy. ester.barbieri2@unibo.it; eleonora.melandri3@unibo.it; simone.roggio@unibo.it \\ ${ }^{\mathrm{c}}$ Department of Architecture (DA), Alma Mater Studiorum, University of Bologna, Viale Risorgimento 2, 40136 Bologna, Italy. \\ angela.santangelo@unibo.it; simona.tondelli@unibo.it; a.ugolini@unibo.it
}

\begin{abstract}
:
Over the last decades, climate change has brought more and more challenges to managers of cultural heritage and researchers. The increasing effects of natural hazards on assets have required the development of a new protocol of techniques and methodologies for the monitoring of Cultural Heritage and the adoption of management plans adapted to the new challenges at every stage of risk management. The work here presented aims at providing an insight of the work undertaken under the framework of the H2020 SHELTER project, to showcase the first steps of the multi-disciplinary research conducted in one of the project's case studies, the complex of Santa Croce in Ravenna, Italy. The paper provides the presentation of the case study and the description of the surveying activities with some first results, to provide a preliminary assessment of the site criticalities to be addressed in the future activities in the area, in line with the EU project expected outcomes.
\end{abstract}

Keywords: 3D surveying, 3D modelling, digital archaeology, cultural heritage, natural hazards, climate change

\section{Introduction}

In recent times, Cultural and Archaeological Heritage has been increasingly threatened by the growing relevance of events related to natural hazards due to the effects of climate change.

The complex of Santa Croce, in Ravenna, once a unique building with the Mausoleum of Galla Placidia, is affected by the recurring hazards encountered in the wide monumental heritage of the city: subsidence and flooding. The area was chosen as a case study of the H2020 SHELTER (Sustainable Historic Environments holistic reconstruction through Technological Enhancement and community-based Resilience) project, which aims at addressing, with a holistic approach, the impacts of climate change on cultural heritage, developing plans for disaster risk management along with protocols and methodologies to enhance the resilience of these areas.

The University of Bologna, a partner of the project, brings together researchers from different fields of expertise that will carry out the activities in the area with an interdisciplinary approach. The work here presented describes the surveying activities that are being undertaken in the archaeological area, showing some first results. The chosen methodology, already successfully applied in other similar case studies by the Geomatics group of the Department of Civil, Chemical, Environmental and Materials Engineering (DICAM), sees the application of different surveying techniques used in integration, with the aim to realize the complete and accurate characterization of all the aspects of the object of interest: geometry, materials, structural behaviour, damaged areas, etc. Geomatics nowadays can offer many techniques devoted to the digitalization, the documentation and the management of objects related to archaeology and built heritage (e.g. loannides \& Quak, 2014; Tucci, Bonora, Conti, \& Fiorini, 2017; Balletti, Bertellini, Gottardi, \& Guerra, 2019; Bitelli et al., 2019; Girelli, Tini, Dellapasqua, \& Bitelli, 2019) and the management of these data inside interdisciplinary researches is of increasing interest. 
In this case study, terrestrial laser scanning and digital photogrammetry, both close-range and aerial by drones, were chosen as they are able to respond to the various and complex requirements of 3D surveying in the field of Cultural Heritage, as for example the high geometric accuracy together with colour fidelity and photorealism. GNSS observations and classical topography by Total Station, on the other hand, provided the georeferencing of all the collected data in the same absolute coordinate system. In addition, thermal images analysis was performed on the interior walls, to investigate and highlight the occurrence of problems related to hygrothermal alterations, which are an often encountered problem on Cultural Heritage (Bitelli, Girelli, Vannucci, \& Pigozzi, 2020).

The final goal of the workflow is the creation of a georeferenced 3D model of the complex system related to the whole area, integrated with other products in support of the multi-disciplinary studies carried out in the framework of the SHELTER project. The collected data will be useful for different purposes: documentation, preservation, restoration, structural health monitoring, GIS and HBIM establishment, touristic exploration (Bitelli, Dellapasqua, Girelli, Sanchini, \& Tini, 2017; Girelli et al, 2019).

\section{The complex of Santa Croce: the Church and the archaeological area}

\subsection{Looking back on the history}

The Santa Croce complex (Fig. 1), located in the historic area of Ravenna, is characterized by the coexistence of different architectures that over time have been layering in the area: the early $17^{\text {th }}$ century Church, the remains of the late-antique Placidian Church and the structures of a Roman domus with part of its mosaics. The Roman remains were attributed to a luxurious residence, coherently with others identified in the surroundings. The studies were undertaken in the area date the domus back to the turn of the $3^{\text {rd }}$ and $4^{\text {th }}$ century $A D$ (Sericola, Agostinelli, \& Ugolini, 2019).

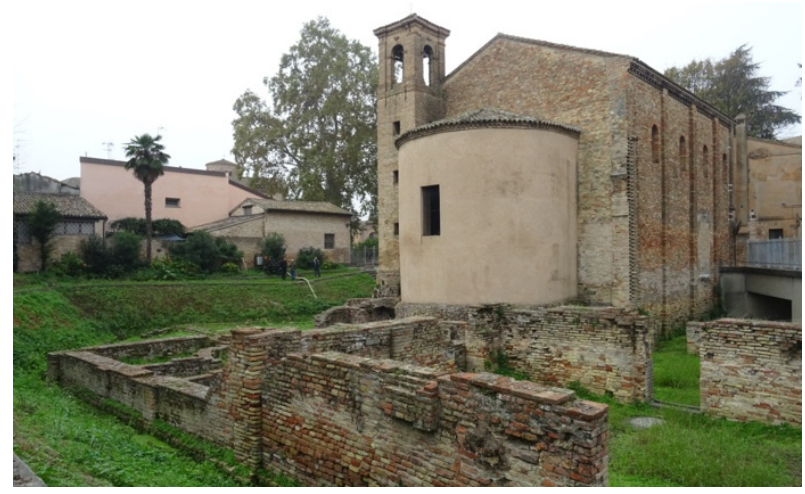

Figure 1: General outer view of the complex of Santa Croce: the Church and the archaeological area.

The late-antique Church, erected between the 424 and the 432 A.D., was built on orders of the Empress Galla Placidia. A narthex completed the single Latin cross nave of the church and shortly afterwards, among other interventions, a sacellum at the South end was added, currently known as the Mausoleum of Galla Placidia. This phase of the Church, in the configuration of a unique building with the Mausoleum, corresponds to its period of greatest magnificence, thanks both to the dimensions of the complex and the presence of the finely decorated mosaic floors (Cassanelli et al., 2013).

Since medieval times, the area has been the subject of several architectural interventions. The current configuration of the Church dates to the $17^{\text {th }}$ century, when several modifications affected what was left of the original structures. The narthex was demolished and the construction of a street separated the southern sacellum from the Mausoleum, consequently requiring the construction of a new facade for the church. In addition, the crosshead and the rectilinear apse were removed, and a new Church with a semi-circular apse flanked by a bell tower was built, corresponding to the last and current architectural configuration of the building.

The archaeological investigations in the area, started in the $20^{\text {th }}$ century, revealed the structures and the different floor levels of the ancient configurations, and continued with several studies and attempts of interventions in the area. Nowadays, the complex, closed to the public, encompasses the Church, whose walls display the different phases of the building, the structures of the first Latin cross plan of the ancient church and the remains of the wall structures and marbles of the domus.

\subsection{Site criticalities}

Among the main potential risks to which the complex of Santa Croce is exposed to, hydrogeological and waterrelated risks are probably those that most affect the archaeological assets. The first excavations undertaken in the area resulted in giving the site a basin configuration. Later, in 1984, to manage the groundwater in the area a pumping system was installed. The intervention, however, worsened the situation of the site, since the pumps drained not only water, but also soil debris, altering the altitude of the archaeological remains and causing loss of stability on the structures (Sericola, Agostinelli, \& Ugolini, 2019).

The area, as well as the rest of the city of Ravenna, is affected by the subsidence phenomena, and results exposed to several water-related risks (Marino, 2019). This major risk factor is linked to the intrinsic characteristic of the wider area around the city and its geomorphological features. The progressive sinking of the soil together with the aquifer proximity to the ground entails a high hydrogeological natural risk for Santa Croce and the surrounding monuments, consequently posing the assets also under flooding risk (Simonini, Ceccato, \& Tosi, 2017).

The flooding hazard is even more relevant as, seen the configuration of the archaeological area, also rainwater and stagnant water constitute a relevant potential risk for the site. Currently, the presence of water is only managed with manually controlled pumps conveying the groundwater into the city sewerage system. However, no early warning system is active in the area, a situation that hiders an immediate response when anomalous situations occur. As happened both in 2016 and 2019, a malfunction of the water pumping system caused sudden flooding of the archaeological area (Fig. 2).

The lack of adequate alarm systems caused a delay in intervention in the area. In addition, as there are currently no well-established and validated emergency management protocols between the managers and 
owners of the area, the implementation of field operations was slow, subjecting the assets to a high risk of loss in case of an abnormal event.

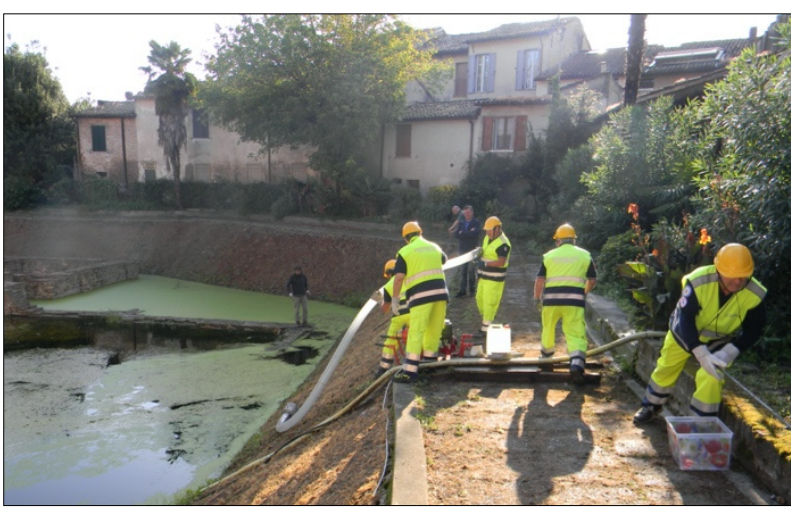

Figure 2: Draining operations of the area after the flooding event in August 2019.

\subsection{SHELTER Project and Ravenna Open}

Lab

The main objective of the SHELTER project (https://www.shelter-project.com) is to provide public authorities and institutions consolidated tools and methodologies for adaptive planning, governance and management of Cultural Heritage, which will be validated during the project lifetime in 5 European Open Labs. The chosen case studies are characterized by different territorial scales, from the cross-regional level to the single building one, and by the different natural hazards to which they are exposed to. The tools and methodologies developed in SHELTER project will be tested and validated in these sites.

The Santa Croce complex has been chosen as one of the five Open Labs of the project, specifically addressing subsidence, flooding and earthquake hazards, and consequently the challenges that are posed to the conservation of the archaeological site. The area will be studied, and methodologies, tools and protocols developed for enhancing the resilience and mitigating the impacts of these hazards.

The first step to achieve these objectives is the global understanding of the risks, natural and non-natural, that affect the assets and the state of conservation of the sites. The University of Bologna cooperates in the project activities with the different institutions involved in a matter of cultural heritage and disaster risk management at a local level, as the local Superintendence, the Diocese and the Municipality of Ravenna, and others at the regional level, as ArpaER (Regional Agency for Prevention, Environment and Energy of Emilia-Romagna). The University fielded diverse expertise placing, thanks to the activities of the project, the study of the complex at the level of European scientific interest.

The first activity that was undertaken, with the aim of documenting the site, reaching a deep understanding of its criticalities and supporting the diagnostic and restoration consequent phases, was the surveying of the area, which allowed the 3D reconstruction of the assets. The work is described in the following paragraph, showing some first results.

\section{Geomatics surveying activities: description and first results}

The surveying operations involved the integration of different techniques: GNSS observations, classical topography with Total Station, Terrestrial Laser Scanning, aerial (by UAV) and close-range digital photogrammetry, thermal images analysis. A careful planning of all the activities allowed the design and the realization of a network for the absolute geo-localization of the acquired data (Fig. 3).
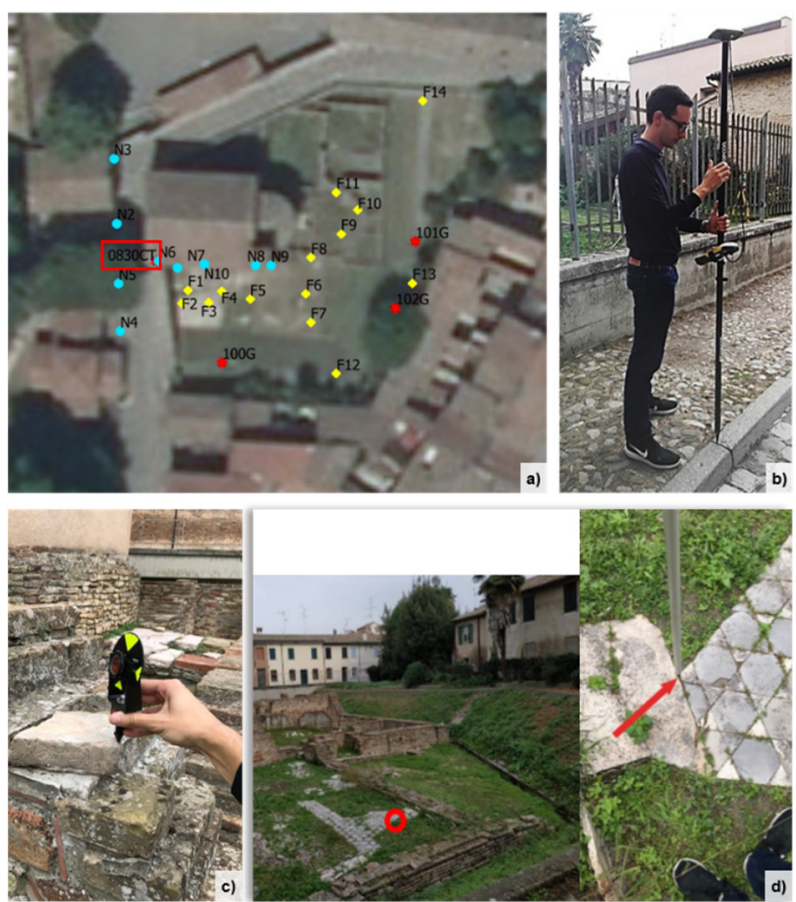

Figure 3: Surveying operations: a) Topographic network; the red stars indicate the GNSS stations, with in the red box the benchmark of the municipal levelling network; cyan and yellow squares indicate respectively targets and natural points used for geo-referencing laser scanning and photogrammetric data; b) a phase of the GNSS survey; in c) and d) two natural control points in the archaeological area.

GNSS observations in NRTK mode were performed for the planimetric network absolute georeferencing, through the survey of three vertices in the area (red stars in Fig. 3). The GRS-1 receiver by Topcon, with PGA-1 antenna, was used and it was connected to NetGEO, the NRTK commercial service provided by the manufacturer. For the altimetric network referencing, the orthometric height of a benchmark of the existing municipal levelling network was used. The position of the benchmark is indicated in Figure 3 by a red rectangle.

The topographic network was surveyed using the firstclass motorized Leica TS30 Total Station $( \pm 0,5$ " angular error, $\pm(0,6 \mathrm{~mm}+1 \mathrm{ppm})$ distance error $)$. Overall, 25 points were measured, both targets and natural points, used as ground control points for geo-referencing laser scanning and photogrammetric data (respectively cyan and yellow squares in Figure 3). The target coordinates were obtained by a least-square adjustment with minimal constraints. 
Figure 4 shows the planimetric drawing of the topographic network. The error ellipses evidenced an uncertainty of 2$3 \mathrm{~mm}$ on the calculated positions.

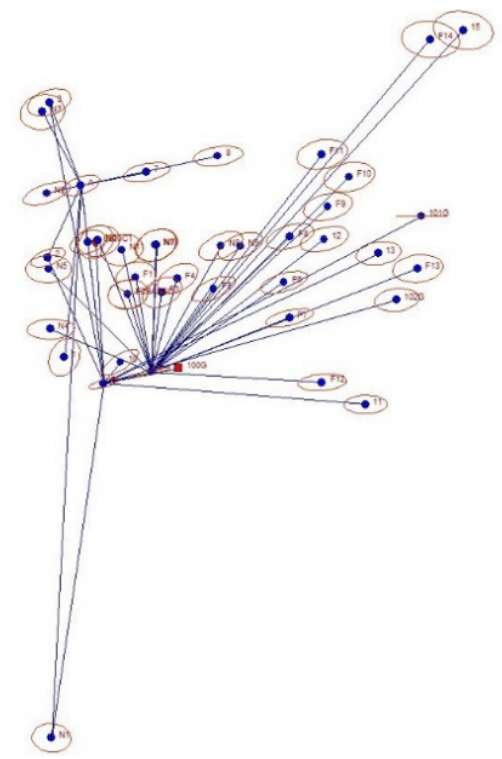

Figure 4: Topographic network drawing; the error ellipses, in red, show uncertainty of 2-3 $\mathrm{mm}$ on the calculated positions (exaggeration factor of 500).

The laser scanner survey of the complex was realized using the time-of-flight (TOF) Riegl VZ400 (declared accuracy $5 \mathrm{~mm}$, precision $3 \mathrm{~mm}$, measurement speed 122000 points/sec) coupled with a Nikon D90 reflex camera. The acquisitions were performed by 15 scanpositions, 7 for the interior, 8 for the exterior (Fig. 5). The number of the measured points is significant: more than 410 million points overall.

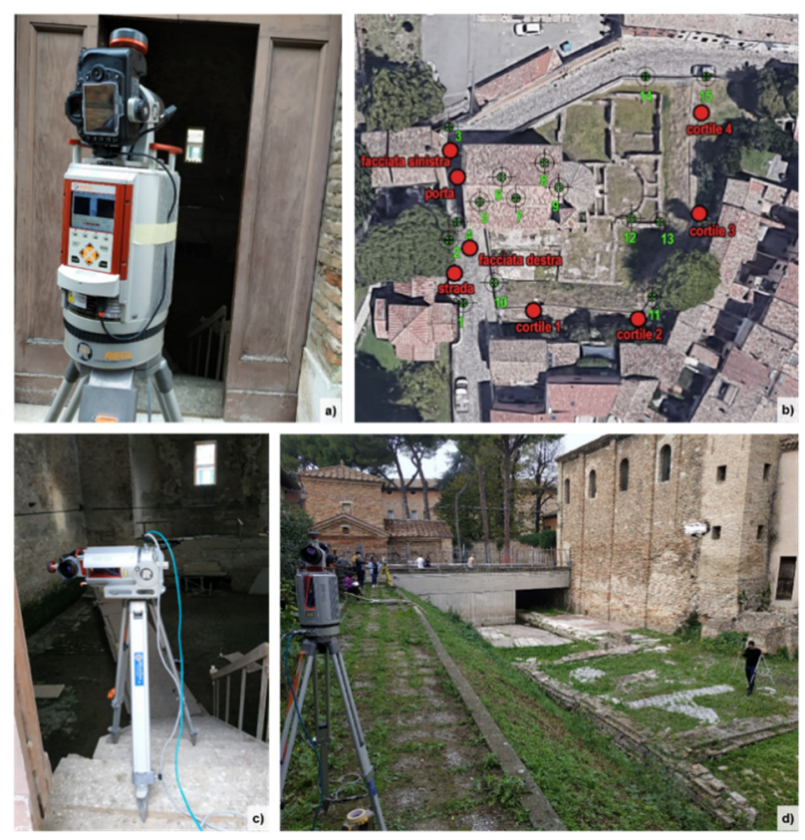

Figure 5: Laser scanning surveys: a) Riegl TOF system; b) scheme of the scan-positions performed for the exterior survey (red circles); c) acquisition of the church ceiling, with the laser tilted horizontally; d) acquisition of the south wall.

In particular, some hidden parts in the archaeological area and the north wall of the church, undetectable by laser scanning due to the fence, were acquired by a closerange photogrammetric survey, whereas in the interior of the church, especially for the apse and the upper part of the truss in the ceiling, an aerial photogrammetric flight by UAV was performed.

In the first case, more than 600 images were acquired using a full-frame DSLR camera, then processed by MultiView Structure-from-Motion approach. The achieved average error was in the order of 1-2 pixel and the obtained point cloud consists of 3.5 million points. Inside the church, two flights with UAV were realized to obtain a detailed model of the apse and a point cloud of the whole interior, especially of the ceiling (Fig. 6). The UAV was a DJI Spark, equipped with FC1102 camera (sensor size $6.17 \times 4.56 \mathrm{~mm}$, resolution $3968 \times 2976$ pixel, pixel size $1.57 \mu \mathrm{m}$, focal length $4.4 \mathrm{~mm}$ ).
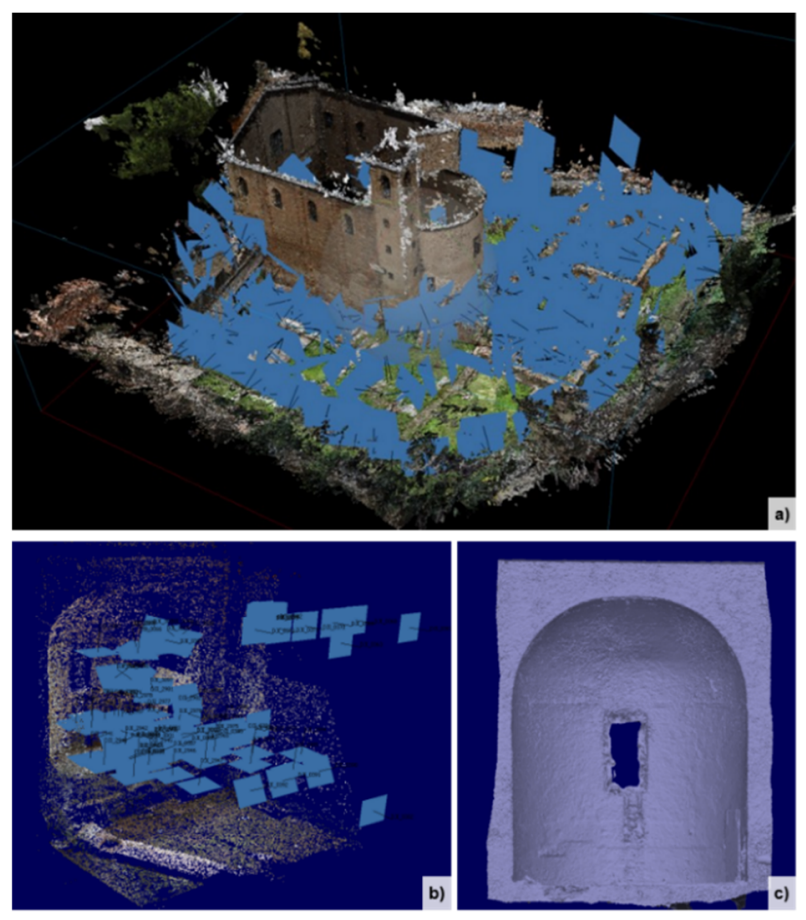

Figure 6: Photogrammetric surveys: a) close-range in the exterior; b) and by drone in the interior; c) the detailed 3D model of the church apse.

All the point clouds obtained by the different techniques were aligned in the absolute reference system established by GNSS and topographic surveys. In particular, the alignment of each TLS point clouds to the reference system adopted, performed by means of the 3D targets, always provided root means square of less than $5 \mathrm{~mm}$. The clouds were then cleaned, fused and filtered. The processing, due to the area complexity and the huge amount of data, required an accurate manual intervention. The alignment between photogrammetric and TLS clouds was realized in two steps: firstly, a coarse registration using manually collimated homologous points and then a fine registration by ICP procedure. The filtering of the outliers was done mostly manually. The TLS model was integrated with data by photogrammetry only where it was lacking, trying to limit the overlapping areas. After the fusion, an automatic resampling was applied, by imposing an average point spacing of $5 \mathrm{~mm}$ (Fig. 7). Considering the integration with the photogrammetric data, the overall reliability of the final model can be evaluated at about $1 \mathrm{~cm}$. 


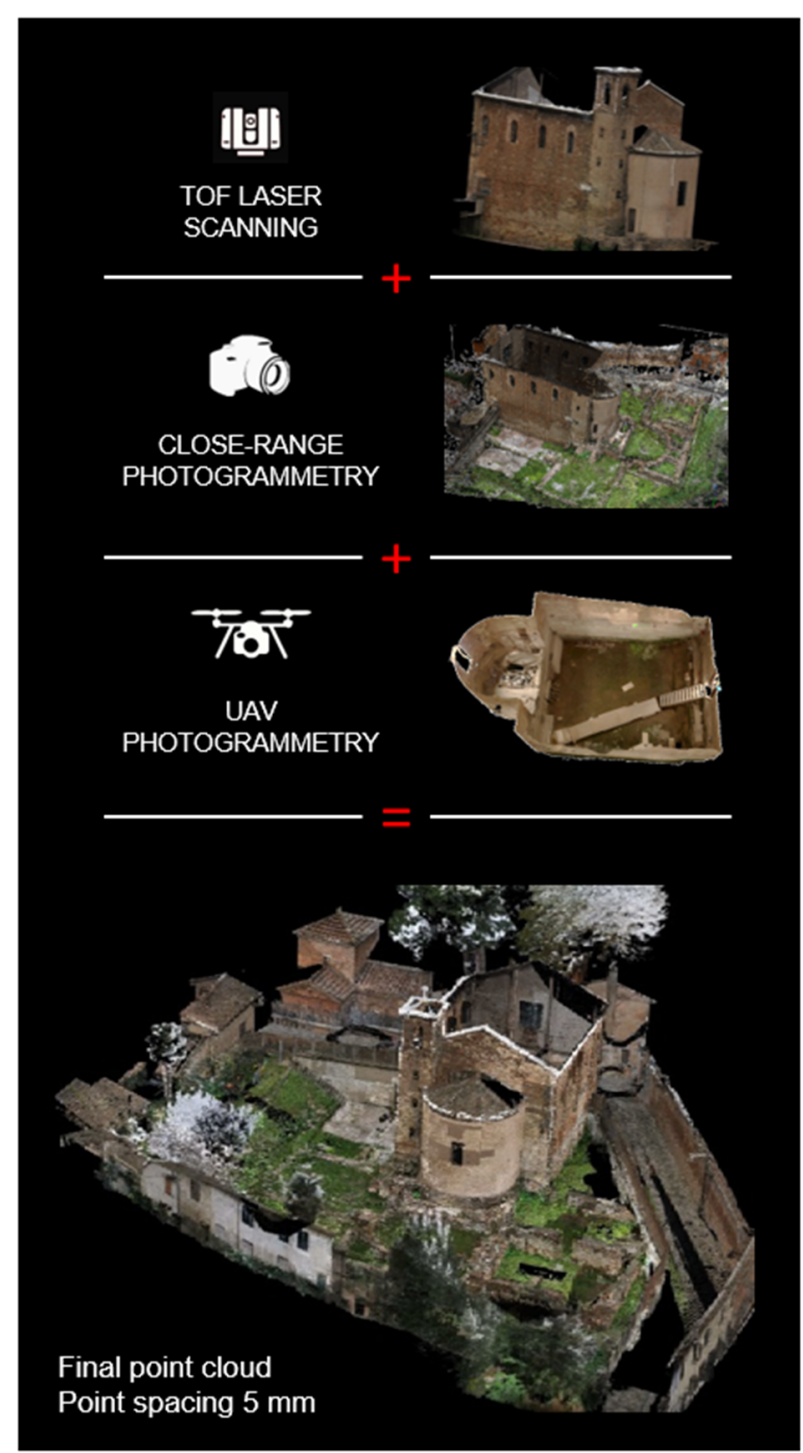

Figure 7: The final point cloud of the complex, obtained fusing together all the acquired data.

Starting from the final point cloud, a simplified BIM model of the Church of Santa Croce was produced (Fig. 8). The BIM model, generated according to an HBIM approach, can represent further support for the knowledge of the current state and its preservation and conservation (Brumana et al., 2020).

As said before, also a diagnostic analysis by thermal imaging (Adamopoulos, Bovero, \& Rinaudo, 2020) was experimented in the interior. The used thermal camera was a FLIR P620, which has a spectral range between $7.5 \mu \mathrm{m}$ and $13 \mu \mathrm{m}, 640 \times 800$ resolution; the camera was equipped with the standard $24^{\circ}$ lens. During the survey, 56 thermal images were acquired. In order to facilitate the focus of the camera and to identify points during postprocessing phase, artificial targets were placed on the masonry. The images were later processed with FLIR software, producing 32-bit tiff files without loss of quality. Thermal images were then edited for easier reading by using a false-colour, to highlight small temperature differences between 17 and $21{ }^{\circ} \mathrm{C}$. Figure 9 shows an example of the acquired thermal images.

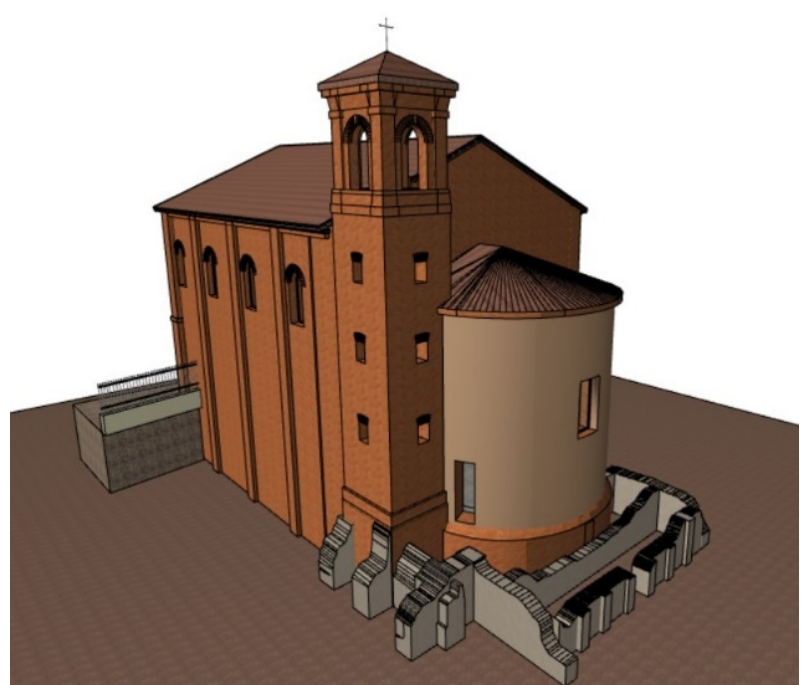

Figure 8: Simplified model of the Church obtained by the HBIM approach.

Some areas remain still incomplete. In the next future, a new survey by UAV will be realized in the exterior, to acquire the roof and to fill some gaps in the archaeological area.

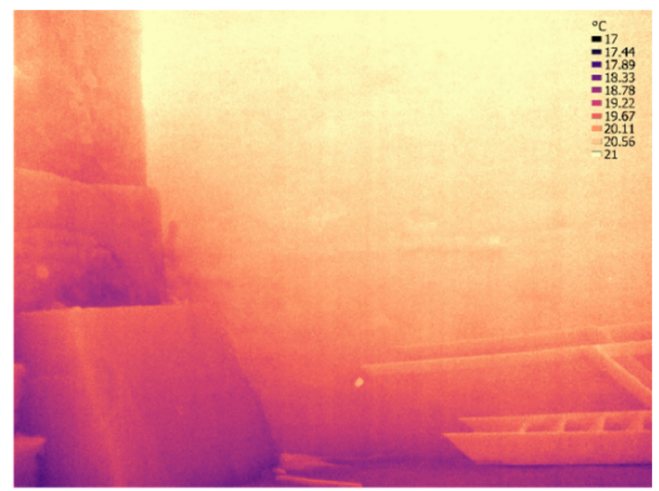

Figure 9: Thermal image of the interior south wall.

\section{Conclusions}

In the framework of the SHELTER project, a highly detailed 3D model of the complex of Santa Croce in Ravenna was produced by the integration of different Geomatics techniques. The acquired data are georeferenced in absolute coordinates and are directly usable in GIS environment, even in large scale analysis. The model and the other generated products will support the many activities involved in the different areas of intervention considered in the project, in a modern multidisciplinary approach.

The creation of the 3D model required important manual editing and harmonization effort, choosing the most appropriate processing methods and approaches according to the peculiarities of the object and the requirements of the project.

By the final point cloud, a simplified model of the church was created using an HBIM approach. The main purpose of this model is not linked to the production of a 3D model strictly reflecting the geometric characteristics of the building but is oriented to integrate the geometric component, with a series of information indispensable for 
the characterization of the existing historical heritage and for the evaluation and design of future recovery and restoration interventions. It is also possible to integrate data from the surveys with different predictive diagnosis tools, through a flow of information of which the BIM model represents the graphic and management interface. Working in a BIM environment also represents an objective advantage, because it is a method that can be used during the entire life cycle of the building or infrastructure, and therefore also includes its management and maintenance phases.

Thanks to the access to the detailed information contained in the model, all the maintenance interventions can be drawn up in a simpler and more intuitive way, facilitating the communication between the various stakeholders involved in the project, simplifying the analysis and design processing phases and optimizing the resources.

\section{Acknowledgements}

This research has received funding from the European Union's Horizon 2020 Research and Innovation Programme under grant agreement no. 821282. This paper reflects only the author's views and neither Agency nor the Commission are responsible for any use that may be made of the information contained therein. Acknowledgements to Superintendence of Archaeology, Fine Arts and Landscape (SABAP) of Ravenna, to the Diocese of Ravenna and the Municipality of Ravenna.

\section{References}

Adamopoulos, E., Bovero, A., \& Rinaudo, F. (2020). Image-based metric heritage modeling in the near-infrared spectrum. Heritage Science, 8, 1-12. https://doi.org/10.1186/s40494-020-00397-w.

Balletti, C., Bertellini, B., Gottardi, C., \& Guerra, F. (2019). Geomatics techniques for the enhancement and preservation of cultural heritage. ISPRS Annals of the Photogramm., Remote Sens. and Spatial Inf. Sci., 42 (2/W11), 133-140. https://doi.org/10.5194/isprs-archives-XLII-2-W11-133-2019

Bitelli, G., Dellapasqua, M., Girelli, V.A., Sanchini, E., \& Tini, M.A. (2017). 3D Geomatics techniques for an integrated approach to Cultural Heritage knowledge: The case of San Michele in Acerboli's church in Santarcangelo di Romagna. Int. Arch. Photogramm. Remote Sens. Spatial Inf. Sci., 42-5/W1, 291-296. https://doi.org/10.5194/isprsarchives-XLII-5-W1-291-2017

Bitelli, G.; Balletti, C.; Brumana, R.; Barazzetti, L.; D'Urso, M.G.; Rinaudo, F.; \& Tucci, G. (2019). The GAMHer Research Project for Metric Documentation of Cultural Heritage: Current Developments. Int. Arch. Photogramm. Remote Sens. Spatial Inf. Sci., 42-2N11, 239-246. https://doi.org/10.5194/isprs-archives-XLII-2-W11-239-2019

Bitelli, G., Girelli, V.A., Vannucci, G., \& Pigozzi, M. (2020). Geomatics as a knowledge base propaedeutic to the restoration of an extended fresco wall. Proc. 2020 IMEKO TC-4 International Conference on Metrology for Archaeology and Cultural Heritage, 22-24 October 2020, Trento, Italy.

Brumana, R., Oreni, D., Barazzetti, L., Cuca, B., Previtali, M., \& Banfi, F. (2020). Survey and Scan to BIM Model for the Knowledge of Built Heritage and the Management of Conservation Activities. In: Daniotti B., Gianinetto M., Della Torre S. eds.: Digital Transformation of the Design, Construction and Management Processes of the Built Environment, pp. 391-400, Springer. https://doi.org/10.1007/978-3-030-33570-0_35

Cassanelli, R., Cirelli, E., Crociati, E., Civiletti, J.P., David, M., Fiorini, A., Jäggi, C., Pasquini, L., \& Scaini, R. (2013). La Basilica di Santa Croce. Nuovi contributi per Ravenna tardoantica. ISSN 1722-1374. Edizioni del Girasole.

Girelli, V. A., Tini, M. A., Dellapasqua, M., \& Bitelli, G. (2019). High resolution 3D acquisition and modelling in Cultural Heritage knowledge and restoration projects: the survey of the Fountain of Neptune in Bologna. Int. Arch. Photogramm. Remote Sens. Spatial Inf. Sci., XLII-2/W11, 573-578. https://doi.org/10.5194/isprs-archives-XLII-2W11-573-2019

loannides, M., \& Quak, E., (2014). 3D Research Challenges in Cultural Heritage. A Roadmap in Digital Heritage Preservation. Springer-Verlag Berlin Heidelberg. https://doi.org/10.1007/978-3-662-44630-0

Marino, L. (2019). II restauro di siti archeologici e manufatti edili allo stato di rudere. Italy, Firenze: Dida Press.

Sericola, M., Agostinelli, E., \& Ugolini, A. (2019). L'area archeologica di Santa Croce. Rischio e degrado come elementi per pianificare il futuro di un sito. Monitoring and maintenance of archaeological areas. Climate change, hydrogeological imbalance, environmental and chemical degradation. International Study Conference. Rome, 20-21 March 2019.

Simonini, P., Ceccato, F., \& Tosi, L. (2017). Effetti della subsidenza sul patrimonio edilizio e infrastrutturale. XXVI National Conference of Geotechnics. 20-22 June 2017, Roma, Italy.

Tucci, G., Bonora, V., Conti, A., \& Fiorini, L. (2017). High-quality 3D models and their use in a cultural heritage conservation project. Int. Arch. Photogramm. Remote Sens. Spatial Inf. Sci., Vol. XLII-2N55, 687-693. https://doi.org/10.5194/isprs-archives-XLII-2-W5-687-2017

UNESCO, ICCROM, ICOMOS, \& IUCN (2010). Managing Disaster Risks for World Heritage. ISBN 978-92-3-104165-5. 